\title{
Lady Frazer e seu marido. \\ Gênero e anomalia na história da antropologia*
}

\author{
Luis Felipe Sobral**
}

\begin{abstract}
Resumo
Dois pontos destacam-se da leitura de Antropólogas \& Antropologia, de Mariza Corrêa, a quem este artigo faz homenagem: primeiro, a importância do gênero como uma categoria para se repensar a história da antropologia; segundo, a capacidade metodológica da anomalia para iluminar as contradições do sistema normativo ao qual se refere. Tais pontos esboçam uma pesquisa em andamento, dedicada ao estudo da posição anômala ocupada pelo antropólogo escocês Sir James G. Frazer na epistemologia da antropologia, a um só tempo denegado por essa disciplina e acolhido pela literatura, e também à circulação de sua obra na França, onde sua esposa, Lady Frazer, desempenhou um papel central. Assim, este artigo busca mostrar o enorme potencial de Antropólogas \& Antropologia para estimular novas pesquisas.
\end{abstract}

Palavras-Chave: $\quad$ Sir James G. Frazer (1854-1941), Lady James G. Frazer (1855-1941), Gênero, Anomalia, História da Antropologia.

* Recebido em 18 de abril de 2018, aceito em 13 de agosto de 2018.

** Pós-doutorando em antropologia social e bolsista da Fapesp na Universidade de São Paulo (USP), São Paulo, SP, Brasil. If_sobral@yahoo.com 
Lady Frazer and Her Husband

Gender and Anomaly in the History of Anthropology

\begin{abstract}
Two points stand out from the reading of Antropólogas \& Antropologia, by Mariza Corrêa: first, the importance of gender as a category for reconsidering the history of anthropology; second, the methodological capacity of anomaly to illuminate the contradictions of the normative system to which it refers. These points outline ongoing research devoted to the study of the anomalous position occupied by Scottish anthropologist Sir James G. Frazer in the epistemology of anthropology, which is simultaneously denied by this discipline and embraced by literature, and also to the circulation of his work in France, where his wife, Lady Frazer, played a central role. Thus, the article seeks to show the enormous potential of Antropólogas \& Antropologia to stimulate new researches.
\end{abstract}

Keywords: Sir James G. Frazer (1854-1941); Lady James G. Frazer (1855-1941); Gender; Anomaly; History of Anthropology. 
1.

O maior perigo que ameaça um livro como Antropólogas \& Antropologia (Corrêa, 2003) é o risco do ressentimento. Ao se debruçar sobre a história da antropologia a partir de uma inflexão de gênero, é tentador hostilizar o establishment masculino e seus recursos habituais para manter, consciente ou inconscientemente, as antropólogas em uma posição dominada. Restringindo-se aos casos estudados por Mariza Corrêa em seu livro, alguns desses recursos são: associá-las à fragilidade, segundo a imagem suscitada pela ornitóloga e etnógrafa Emilia Snethlage em suas expedições; considerar inadequadas suas atitudes, como o esforço da sertanista e feminista Leolinda Daltro em civilizar os índios; questionar-lhes a competência, como no episódio eleitoral do Museu Nacional no qual sua diretora, Heloisa Alberto Torres, foi acusada de negligenciar o acervo; enfim, denegrir-lhes o renome, um recurso particularmente perverso que afligiu a antropóloga Ruth Landes, perseguida dentro e fora do país no âmbito dos estudos afro-brasileiros. Talvez essa hostilidade em relação à postura do establishment masculino seja inevitável, um efeito comum da análise dos sistemas de dominação, na qual a empatia inclina-se em geral aos dominados; mas ela é também um produto do julgamento cômodo que se pode realizar a respeito de um mundo social que o tempo consumiu: a falsa familiaridade que se pensa reconhecer nas relações de força desse mundo conduz, de um lado, à empatia, de outro, ao ressentimento. E o ressentimento não leva senão, na melhor das hipóteses, a tentativas vãs de reabilitação de personagens históricas que, de um certo ponto de vista presente, perderam o jogo. É justamente esse perigo que Mariza Corrêa evita em seu livro, parte de um estudo mais amplo sobre a história da antropologia. ${ }^{1}$

O objetivo mais geral de Antropólogas \& Antropologia é compreender como os constrangimentos de gênero sobrepõem-se em algumas situações a outros marcadores sociais, tais como

1 Sobre os resultados desse estudo mais amplo, ver Corrêa (2013), assim como a resenha que Ramassote (2017) lhe dedicou. 
classe, educação e compadrio. Os casos escolhidos, alguns deles citados acima, são particularmente convenientes na medida em que fornecem os dados necessários para a reconstrução das trajetórias sociais dessas antropólogas. Nesse sentido, pode-se dizer que elas são excepcionais: primeiro, porque os traços de sua presença não se apagaram suficientemente para impedir tal reconstrução, como ocorreu com tantas outras; segundo, porque, sendo solteiras e dedicando-se às respectivas carreiras, elas furtaram-se ao estatuto frequente de auxiliar de pesquisa, ou simplesmente esposa, do marido antropólogo. Esse trabalho de reconstrução não perde de vista a espessura histórica própria dessas trajetórias, o que impede uma apreensão homogênea $e$ estável dessas mulheres: assim, se de um lado ressaltava-se a presença frágil de Emilia Snethlage na selva amazônica, de outro ela era vista como varonil, dado o caráter aventuresco próprio desse tipo de empreitada. Ademais, tal procedimento permite questionar a própria ideia de sucesso e fracasso profissional: ainda que, a despeito de seus esforços, Heloisa Alberto Torres não tenha conseguido fazer do Museu Nacional o centro da antropologia que tinha em mente, essa instituição acabou por se tornar subsequentemente o centro da etnologia brasileira, o que é sem dúvida um resultado de seu trabalho. Vê-se então que o imenso valor desses casos, interpelados dessa maneira, reside em sua capacidade de perturbar uma interpretação unívoca do mundo social e da história dos quais eles fazem parte. Essas antropólogas "preenchem [...] uma espécie de interregno nessa galeria de figuras da história da antropologia", escreve Mariza Corrêa,

constituindo-se como seres de natureza imaginária, por estarem fora de seu espaço "natural", sem terem sido admitidas ao novo espaço social que procuravam ocupar: nem homens, nem mulheres, em termos culturais: seres anômalos, aparentados antes aos monstros do que à raça humana (Corrêa, 2003:32, grifo da autora). ${ }^{2}$

\footnotetext{
2 Vale assinalar que a autora considera também a noção de raça, na medida estrita em que ela se articula com as constrições de gênero, sobretudo no caso de
} 
Da perspectiva epistemológica, uma pesquisa interessada em anomalias é sem dúvida intelectualmente mais rica que outra focalizada sobre regras; isso porque as anomalias pressupõem de imediato as regras, mas estas são incapazes de prever aquelas; do contrário, as anomalias não existiriam. As anomalias apresentam um caráter imponderável e, justamente por isso, encerram um potencial de disrupção do sistema normativo ao qual se referem, expondo assim seus impasses e contradições (Ginzburg, 2004). Antropólogas \& Antropologia produz tal efeito de duas maneiras no âmbito da história da antropologia. Primeiro, ele demonstra a importância crucial da categoria gênero como uma forma de conhecimento dessa história, uma vez que o acesso e o bloqueio à profissão antropológica eram constrangidos, senão determinados, em certas situações por fatores de gênero; portanto, essa categoria não é, ou não apenas, um produto ideológico do feminismo, mas um fator social objetivo que provoca efeitos concretos. Segundo, o livro de Mariza Corrêa recusa completamente a história habitual da antropologia, com sua procissão de autores canônicos, a maioria homens, remontando à revolução de Bronislaw Malinowski e cuja presença aí justifica-se pela contribuição teórica feita à disciplina; tudo o que se passou aquém desse período $e$ além das páginas de teoria permanece ignorado. Mais uma vez, não se trata de reabilitar antropólogas e antropólogos pouco conhecidos, ou mesmo absolutamente obscuros, em detrimento de outros que contribuíram inequivocamente com o desenvolvimento teórico da disciplina. O raciocínio proposto consiste na verdade em um esforço de afastar-se do debate corrente, que trata essa história segundo uma concepção teleológica, para interpelá-la em outros termos, ainda que, evidentemente, não deixem de ser formulados no presente e de manter um vínculo profundo com tal debate, mesmo que seja a contrapelo; dessa maneira, torna-se possível redigir uma outra

Ruth Landes, cujo relacionamento amoroso com o folclorista Edison Carneiro alimentou os comentários pejorativos de seus detratores; sobre Carneiro, ver Rossi (2015). 
história da antropologia, mais complexa e interessante porque, ao contrário da versão depurada, é capaz de apreender os impasses e contradições constituintes do desenvolvimento da disciplina conforme ela se fazia. ${ }^{3}$

As antropólogas de Antropólogas \& Antropologia não se referiam às dificuldades profissionais que enfrentavam como constrições de gênero, mas estas estavam sem dúvida presentes; o termo ético que nos interessa hoje carece então do conteúdo êmico que, nesse caso, só uma démarche propriamente histórica pode apreender, daí a necessidade de se debruçar sobre cartas, diários, monografias, resenhas, relatórios e assim por diante, ou seja, as mediações indispensáveis entre o presente e o passado. Essa história da antropologia declinada segundo critérios de gênero traça assim uma linhagem feminina da disciplina. Seu resultado instantâneo consiste em provocar um estranhamento diante da procissão de autores canônicos, que já não podem então ser vistos simplesmente como tais: qual seria o cânone antropológico se, idealmente, as constrições de gênero não existissem ou se elas fossem diferentes? Ao mesmo tempo, com sua ênfase no gênero $e$ na anomalia, tal história lança os fundamentos necessários para alimentar novas pesquisas, como a que se esboça a seguir, ainda em sua primeira formulação.

2.

"Frazer é um constrangimento", afirma convicto Robert Ackerman na introdução à biografia que dedicou ao antropólogo escocês Sir James George Frazer; ele continua: "O homem que teve mais leitores $e$ foi indiscutivelmente um melhor escritor que qualquer outro antropólogo escrevendo em inglês não aparece em nenhuma das linhagens profissionais que os antropólogos reconhecem hoje" (Ackerman, 1990:1). ${ }^{4}$ Segundo o biógrafo, ao

3 Sobre o problema do presentismo na história da antropologia, ver Stocking, Jr. (1982).

4 "Frazer is an embarrassment. The man who has had more readers and who was arguably a better writer than any other anthropologist writing in English does 
contrário de outros de seus contemporâneos, tais como E. B. Tylor, Lewis Henry Morgan, J. F. McLennan e William Robertson Smith, as contribuições de Frazer à disciplina não sobreviveram ao desafio do tempo: ele não pertence ao futuro. ${ }^{5}$ Ainda que Ackerman não deixe de ter razão, isso não significa que Frazer tenha desaparecido do debate antropológico ao longo do século. É justamente o contrário que se passa; em contrapartida, sua evocação implica sempre um distanciamento: Marshall Sahlins (1987) refere-se ironicamente a ele ao examinar a morte do capitão Cook no Havaí, e Marilyn Strathern (1987) critica veementemente a possibilidade de um retorno pós-moderno a Frazer, para citar apenas dois exemplos. Até mesmo quando há um interesse mais desarmado por sua obra, impõe-se a necessidade de uma justificativa cautelosa, como faz Michael Taussig (1993) ao examinar o aspecto mimético da magia simpática. Essa presença persistente manifesta-se inclusive de forma institucional: os artigos citados de Sahlins e Strathern, por exemplo, foram ambos apresentados nas Frazer Lectures, um prestigioso ciclo de conferências que, remontando a 1922 e incluindo antropólogos do calibre de Max Gluckman, Claude LéviStrauss e Veena Das, alterna-se anualmente entre quatro universidades britânicas. ${ }^{6}$ Assim, ainda que nenhuma linhagem o reivindique, Frazer certamente não deixou a cena antropológica.

not appear in any of the professional lineages that anthropologists acknowledge today". Salvo indicação contrária, todas as traduções são minhas.

${ }^{5}$ Como assinala Ackerman (1990), Tylor é considerado o fundador da antropologia e estabeleceu tal disciplina no âmbito acadêmico, em Oxford; Morgan demonstrou a importância dos sistemas classificatórios para os estudos de parentesco; McLennan e Robertson Smith defenderam a abordagem sociológica para se compreender as religiões primitivas. Vale lembrar que, apesar de haver discordâncias, atribui-se a Tylor a formulação da noção moderna de cultura: ver Kuper (1999). Enfim, quanto à atribuição de fundador da antropologia a Tylor, ela está longe de ser unânime, mas ele contribuiu sem dúvida na sua implantação acadêmica.

6 A origem das Frazer Lectures refere-se à coincidência entre a conclusão, em 1913, da terceira edição de O ramo de ouro (Frazer, 1911-1915) e o sexagésimo aniversário de seu autor, estimulando um grupo de amigos e colegas a 
Se um dos aspectos assinalados por Ackerman refere-se à ausência de Frazer nas linhagens antropológicas, o outro concerne sua popularidade entre o público leitor $e$ a qualidade de sua escrita. Não há dúvida que Frazer possuía uma dupla ambição, a um só tempo científica e literária; ele próprio afirma-o inúmeras vezes e, em uma carta ao poeta e amigo Sir Edmund Gosse, mostra-se particularmente consciente do impasse criado por essa posição: "Os cientistas [...] provavelmente desprezam-me como um mero cavalheiro literário, enquanto os cavalheiros literários desprezam-me como um mero cientista" (Frazer, 2005:316). ${ }^{7}$ Dessa perspectiva, talvez tenha se passado com ele, ao menos em parte, algo análogo ao que ocorreu com Buffon no século XVIII: conforme a ciência procurava se distinguir da literatura, não lhe foi mais possível pautar sua célebre reputação de historiador natural fundamentalmente no estilo de seu texto, ainda que nesse quesito, tal como Frazer, ele fosse indiscutivelmente um mestre (Lepenies, 1988). A pesquisa de campo, o esforço em descrever a perspectiva nativa, a comparação segundo unidades culturais, a desconfiança do racionalismo: cada uma das características da antropologia moderna, que ambicionava um estatuto científico, opõe-se à antropologia de Frazer, deixando-lhe assim de mãos vazias, exceto por seu estilo elegante. ${ }^{8}$ É claro que a maioria de seus contemporâneos carecia igualmente de algumas, senão todas, dessas características que, reunidas, configuravam uma inovação

estabelecer um fundo destinado a promover pesquisas etnográficas, pois, apesar do próprio Frazer nunca ter realizado uma, ele defendia sua importância, tendo sido por exemplo um grande entusiasta das expedições australianas de Baldwin Spencer e Francis Gillen, cujos primeiros resultados ele ajudou a publicar com seu editor, Macmillan (Spencer; Gillen, 1899); o início da guerra impôs um adiamento no projeto, que, quando retomado, viu-se enfim transformado em uma lectureship devido à inflação e, provavelmente, às hesitações de Frazer, sempre modesto demais em aceitar homenagens (Ackerman, 1990).

7 "The scientific men [...] probably despise me as a mere literary gent, while the literary gents look down on me as a mere scientific man" (carta de Sir James G. Frazer a Sir Edmund Gosse, Pontresina, 2 de julho de 1912).

8 Mas isso não significa que a antropologia tornou-se inequivocamente científica por referência à literatura; ver por exemplo Clifford (1988). 
decisiva; entre eles encontram-se aquelas mesmas figuras reivindicadas pelas linhagens futuras da disciplina, cujas contribuições lhes salvaram porém do esquecimento. Por que então Frazer, desprovido de contribuições, o exilado das ilhas (britânicas), segundo a expressão muito conradiana de Stocking (2001), não deixou a cena antropológica?

Tal questão abrange somente parte do problema, que não pode ser formulado inteiramente sem sua contraparte, que se refere justamente ao espaço para onde se remetem aqueles munidos somente de estilo: a literatura. Talvez Frazer tivesse razão ao identificar, antes da Primeira Guerra, um desprezo nos olhares que os "cavalheiros literários" lhe dirigiam; no pós-guerra contudo esse sentimento não teria absolutamente lugar, pois daí em diante seu apelo seria imenso e duradouro. É significativo que, no momento preciso em que a obra de Frazer deixava de fazer sentido para os antropólogos, ela passava a alimentar a produção literária de escritores como William Butler Yeats, T. S. Eliot, D. H. Lawrence e James Joyce, entre muitos outros (Vickery, 1976). Não se trata de um episódio isolado; ao longo do século, seu apelo no meio literário, e artístico em geral, não se arrefeceu. Assim, $O$ ramo de ouro encontra-se entre as leituras de cabeceira de Kurtz, o coronel renegado que Marlon Brando interpreta em Apocalypse Now, o épico de Francis Ford Coppola sobre a guerra do Vietnã. ${ }^{9}$ Mais recentemente, a música americana Patti Smith (2010) relata como certa vez, nos anos 1960, visitou uma livraria esotérica em busca da terceira edição de $O$ ramo de ouro; nesse caso, tal visita, e a leitura daí decorrente, parece ter se realizado como uma espécie de Frazer-trip. Por último, é no interior mais uma vez de um exemplar de $O$ ramo de ouro que o narrador de $O$ irmão alemão, de Chico Buarque (2014), depara-se com uma carta que provocará um impacto em suas relações familiares. ${ }^{10}$ Os exemplos

9 Apocalypse Now, dirigido e produzido por Francis Coppola, Omni Zoetrope, 1979, 146 min.

${ }^{10}$ Agradeço a Fernanda Peixoto e Maurício de Almeida por terem respectivamente me chamado a atenção para esses dois livros. 
poderiam continuar: com destaque para $O$ ramo de ouro, Frazer dá provas inequívocas de uma grande capacidade de irradiação entre os escritores e artistas.

A presença de Frazer na antropologia parece se manifestar como uma espécie de fantasmagoria, assombrando a disciplina à medida que ela não mais se reconhecia nele, fazendo-se na verdade contra ele a partir de um certo momento difícil de se precisar, mas que se convencionou situar por volta da ascensão de Malinowski. A antropologia que se seguiu poderia então ser definida como uma antropologia anti-frazeriana. Nesse sentido, como o elemento afastado do espaço epistemológico da disciplina no processo mesmo de constituição deste, Frazer ocuparia aí uma posição central, ainda que tácita, daí suas constantes reaparições, que os antropólogos denegam prontamente - no intuito de afirmar a antropologia, seria preciso negar Frazer. Enquanto isso, sua obra alimentava uma produção literária $e$ artística heterogênea ao longo de todo o século: fora de contexto, em um caso, plenamente dentro de contexto, no outro, para empregar os termos de Strathern (1987). Não é possível compreender esse descompasso simplesmente como um produto da oposição entre ciência e literatura. Primeiro, porque isso pressupõe o raciocínio teleológico de um nascimento científico da antropologia, instaurando assim uma linha temporal unívoca em direção ao presente; segundo, porque esse projeto de uma antropologia científica nunca se realizou plenamente, deparando-se com impasses reveladores (Debaene, 2010). Na verdade, esse descompasso situa Frazer em uma posição anômala, que se pode denominar de nexo epistemológico, da qual se vislumbra em um reflexo invertido toda a história da antropologia, fornecendo assim os elementos necessários à redação de uma anti-história da disciplina, isto é, a história do que a antropologia rejeitou e que permanece indispensável como rejeição para que ela busque ser o que ambiciona ser em cada momento de sua história. 
3.

O projeto intelectual de se escrever uma anti-história da antropologia a partir da posição anômala de Frazer ao longo do século consiste certamente em uma pesquisa de longo fôlego, pois ele acomoda diversos recortes possíveis e encerra vários desdobramentos imprevistos. A palavra-chave para realizá-lo é circulação, uma vez que é justamente a circulação da obra de Frazer entre antropologia e literatura que permite flagrar sua posição epistemológica singular. É preciso então compreender em detalhes como essa obra circulava e, para tanto, é necessário circular junto com ela.

O espaço de circulação mais restrito do próprio Frazer, o mundo acadêmico britânico e suas imediações, foi relativamente bem estudado, ${ }^{11}$ assim como as apropriações que os modernistas anglófonos fizeram de sua obra até a Segunda Guerra (Vickery, 1976). A etapa seguinte desse processo de circulação ocorre na França, pois aí o número de traduções de sua obra excede o de qualquer outro país: de 1898 a 1941, quando Frazer falece, contam-se 38 traduções. ${ }^{12}$ Entre elas, encontram-se não somente cientistas sociais, como Arnold Van Gennep, um dos tradutores do primeiro estudo de Frazer sobre o totemismo, e filósofos, como Lucien Lévy-Bruhl, prefaciador do volume bibliográfico de $O$ ramo de ouro, mas também escritores, como Paul Valéry, que assinou o prefácio do primeiro tomo de The Fear of the Dead in Primitive Religion e a condessa Jean de Pange, tradutora da conclusão de Totemism and Exogamy (Frazer, 1898; Lévy-Bruhl, 1930; Valéry, 1934; Frazer, 1923a). Mais uma vez, vislumbra-se o duplo caráter da obra de Frazer entre antropologia e literatura. Esse caráter não pode contudo ser inteiramente entendido se apartado da rede de comunicação da qual essas traduções são o

\footnotetext{
${ }^{11}$ Além da biografia e da coletânea de cartas já citadas (Ackerman, 1990; Frazer, 2005), Ackerman estudou as apropriações que os chamados Ritualistas de Cambridge fizeram da obra de Frazer: ver Ackerman (2002).

${ }^{12} \mathrm{O}$ bibliógrafo de Frazer, Theodore Besterman (1934), registra 31 traduções francesas; pesquisando na Bibliothèque nationale, encontrei outras sete entre a publicação dessa bibliografia e a morte de Frazer.
} 
índice, ligando Frazer aos intelectuais e escritores franceses. Ainda que Ackerman não inclua nenhuma carta dessa rede na coletânea que organizou, ele assinala sua existência (Ackerman, 2005). O volume dessa correspondência é de fato imenso e, percorrendo inúmeros arquivos e bibliotecas na França $e$ na Inglaterra, pude reunir um pouco mais de 1400 cartas, uma prova incontestável da rede vigorosa que ligava Frazer aos intelectuais, escritores $e$ editores franceses, entre eles Marcel Mauss, Claude Aveline e Paul Geuthner, além dos já citados. ${ }^{13}$ Nessa massa de documentos, um fato se distingue: a maior parte das cartas foi enviada ou recebida por Lady Frazer, não por seu marido. ${ }^{14}$ Trata-se de uma informação capital, que a identifica como um dos personagens mais importantes, senão o mais importante, dessa rede da qual ela era sem dúvida o pivô. A partir da virada do século, todas as traduções francesas da obra de Frazer foram realizadas ou coordenadas por ela, que contava com a carta branca de Macmillan, o editor inglês de seu marido. Sem esse trabalho minucioso e monumental, o número dessas traduções seria certamente muito menor e a disseminação da obra de Frazer do outro lado da Mancha, muito mais restrita. ${ }^{15} \mathrm{~A}$ pesquisa sobre essa circulação passa portanto por Lady Frazer.

Pouco se sabe sobre Lady Frazer. As informações disponíveis encontram-se fundamentalmente ao longo da biografia que Ackerman dedicou ao seu marido. Nascida Elizabeth (Lilly) de

\footnotetext{
${ }^{13}$ Essa pesquisa foi realizada com o apoio de uma bolsa da Fapesp (processo 2016/10.514-0).

${ }^{14}$ Segundo uma contagem rápida, Lady Frazer recebeu 287 cartas dos correspondentes franceses e enviou 770; quanto a Frazer, ele recebeu 209 cartas e enviou 163. Isso significa, primeiro, que Lady Frazer era a destinatária ou a remetente de mais de dois terços dessa correspondência; segundo, que ela redigiu mais da metade.

${ }^{15}$ Vale assinalar que essa circulação na França implica na verdade uma disseminação da obra de Frazer por um circuito francófilo mundial: Mário de Andrade, por exemplo, leu a versão resumida de $O$ ramo de ouro em sua tradução francesa, realizada pela própria Lady Frazer (Frazer, 1923b), segundo o exemplar com marginália preservado em sua coleção (Instituto de Estudos Brasileiros, Universidade de São Paulo, acervo Mário de Andrade, MA3684-1).
} 
Boys na França, provavelmente em 1855, talvez de origem judaica, ela casou-se com um marinheiro britânico, com quem viajou bastante e teve dois filhos; diante da morte repentina do marido, ela buscou seu sustento na escrita, obtendo um contrato para redigir um livro sobre história da dança (Grove, 1895); a pesquisa para um dos capítulos do livro, "as danças dos selvagens", levou-a à Cambridge, onde conheceu Frazer em 1894; dois anos depois, eles se casaram. Daí em diante, ela dedicou-se substancialmente a três atividades: a administração de sua rotina doméstica, a promoção da obra do marido e a redação de seus próprios livros, dedicados ao ensino da língua francesa às crianças britânicas. ${ }^{16}$ Ela faleceu em 1941, somente algumas horas após o marido (Ackerman, 1990). Todos os testemunhos, sejam de homens ou mulheres, que lhe fazem referência parecem concordar em linhas gerais com a descrição apresentada por Malinowski em seu obituário de Frazer: ela era "capaz e enérgica, embora um pouco temível" e "inquestionavelmente um elemento intrigante para a maioria dos amigos de Frazer assim como na posição deste no mundo acadêmico" (Malinowski, 1960:181).

Ao que tudo indica, o caráter intrigante atribuído à Lady Frazer remete a um problema de gênero, pois seu comportamento não se adequava à expectativa associada ao gênero feminino que então lhe cabia segundo sua condição de mulher; na verdade, a própria possibilidade dessa inadequação assinala o caráter arbitrário do vínculo entre esse gênero e essa condição. Ela não deixava sem dúvida de desempenhar a função de esposa, administrando a vida doméstica compartilhada pelo casal, redigindo seus livros, cujo tema pedagógico adequava-se perfeitamente a essa função, e assinando-os com o nome do marido: como bem mostram os títulos citados, Mrs. Lilly Grove torna-se primeiro, ao se casar novamente, Mrs. J. G. Frazer; em seguida, quando seu marido recebe o título de cavaleiro, em 1914, ela transforma-se em Lady J. G. Frazer. Em contrapartida, ao assumir sem hesitar a tarefa árdua de promover a obra do marido,

${ }^{16}$ Entre inúmeros outros, ver por exemplo Frazer (1904; 1921). 
reivindicando incessantemente o reconhecimento que julgava lhe caber por mérito, ela ultrapassava a função de esposa; de fato, ela estava à frente da correspondência de seu marido e do imenso trabalho de tradução de sua obra em francês, daí o caráter intrigante: ela encontrava-se fora de categoria, ocupando uma posição intermediária entre a função de esposa $e$, na falta de um termo melhor, de agente de Frazer. A essa indeterminação de gênero pode-se acrescentar ainda seu estatuto duplamente ambíguo em referência à nacionalidade, como francesa na Inglaterra, e à educação, como outsider em um mundo acadêmico que, ademais, era fundamentalmente masculino. ${ }^{17}$ Assim fazendo, ousando sair do espaço feminino que lhe era imposto para empreender com êxito uma atividade intelectual em território masculino, provando sua capacidade, sua energia, e revelando-se às vezes temível, seu nome por aliança deixava de fazer referência simplesmente ao seu marido - "a esposa de Frazer" - para conquistar uma autonomia relativa e, vale dizer, um renome (Corrêa, 2003; Pontes, 2010). Dessa perspectiva, Frazer é que era "o marido de Lady Frazer". Considerando portanto o protagonismo desempenhado por Lady Frazer na circulação da obra de seu marido na França, a compreensão plena dessa circulação exige consequentemente a compreensão desse protagonismo. ${ }^{18}$

4.

Antropólogas \& Antropologia consiste em um duplo desafio lançado ao essencialismo. Antes de tudo, ao essencialismo de gênero: debruçando-se sobre a trajetória social anômala de certas antropólogas que lograram estabelecer, com mais ou menos

\footnotetext{
${ }^{17}$ Ver, por exemplo, o livro que Mary Beard dedicou à classicista Jane Ellen Harrison, uma das Ritualistas de Cambridge: Beard (2002).

${ }^{18}$ Essa pesquisa sobre a circulação de Frazer na França, pautada no cruzamento da correspondência com as traduções e sua recepção, será publicada como um volume dos "Carnets de Bérose", a coleção dedicada à história da antropologia e coordenada por Christine Laurière e Frederico Delgado Rosa no âmbito do projeto Bérose (Encyclopédie en ligne sur l'histoire de l'anthropologie et des savoirs ethnographiques): ver www.berose.fr.
} 
sucesso, uma carreira própria, ultrapassando assim o estatuto que lhes era atribuído de esposa ou, no máximo, auxiliar de pesquisa do marido antropólogo, Mariza Corrêa demonstra o caráter completamente arbitrário desse estatuto. Em seguida, ao essencialismo histórico: uma vez que as constrições de gênero são fatores sociais objetivos, provocando assim efeitos concretos com os quais essas antropólogas tiveram que lidar em suas trajetórias, as linhagens antropológicas que conduzem ao presente segundo um critério exclusivo de contribuição teórica não podem mais ser vistas como evidentes. Na elaboração desse duplo desafio, não é fortuito então que a autora valorize justamente as anomalias, pois os elementos anômalos são aqueles que, precisamente, concentram uma capacidade maior de revelação dos impasses profundos das regras estabelecidas às quais se referem $e$, portanto, também de questionamento das ideias prontas das quais o mundo acadêmico não é sem dúvida isento. Tudo isso não implica de forma alguma a reabilitação dessas antropólogas; na verdade, seu valor maior reside na função heurística que desempenham, configurando assim um problema de vasto alcance para se pensar e se escrever a história da disciplina. Dessa maneira, o potencial de Antropólogas \& Antropologia em continuar alimentando novas pesquisas é imenso e absolutamente necessário.

\section{Referências bibliográficas}

ACKERMAN, Robert. J. G. Frazer. His Life and Work. Cambridge, Cambridge University Press, 1990.

. The Myth and Ritual School. J. G. Frazer and the Cambridge Ritualists. Nova York e Londres, Routledge, 2002.

. General Introduction. In: FRAZER, Sir J. G. Selected Letters of Sir J. G. Frazer. Oxford, Oxford University Press, 2005, pp.1-16.

BEARD, Mary. The Invention of Jane Harrison. Cambridge, Massachusetts, Harvard University Press, 2002.

Besterman, Theodore. A Bibliography of Sir James George Frazer. Londres, Macmillan and Co., 1934. 
BuARque, Chico. O irmão alemão. São Paulo, Companhia das Letras, 2014.

CLIFFORD, James. On Ethnographic Self-Fashioning. In: . The Predicament of Culture. Twentieth-Century Ethnography, Literature, and Art. Cambridge, Massachusetts, Harvard University Press, 1988, pp.92-113.

CoRRÊA, Mariza. Antropólogas \& Antropologia. Belo Horizonte, Editora UFMG, 2003.

- Traficantes do simbólico e outros ensaios sobre a história da antropologia. Campinas, Editora da Unicamp, 2013.

DEBAENE, Vincent. L'adieu au voyage. L'ethnologie française entre science et littérature. Paris, Gallimard, 2010.

FrAzer, J. G. Le Totémisme. Étude d'ethnographie comparée. Paris, Librairie C. Reinwald, Schleicher Frères, Éditeurs, 1898.

. The Golden Bough. A Study in Magic and Religion. Londres, Macmillan and Co., 1911-1915, 12 vols. $1923 a$.

Les Origines de la famille et du clan. Paris, Paul Geuthner, . Le Rameau d'or. Édition abrégée. Paris, Librairie orientaliste Paul Geuthner, $1923 b$.

. Selected Letters of Sir J. G. Frazer. Oxford, Oxford University Press, 2005.

Frazer, Mrs. J. G. Émile et Hélène. A French Primer. Londres, Macmillan and Co., 1904.

FrAzER, Lady J. G. Berthe aux grands pieds. Adapted from the Poem of Adenet and Retold for the Young in Modern French. Londres, A. \& C. Black, 1921.

GINZBURG, Carlo. Family Resemblances and Family Trees: Two Cognitive Metaphors. Critical Inquiry (30/3), Chicago, The University of Chicago Press, 2004, pp 537-556.

Grove, Mrs. Lilly. Dancing. Londres, Longmans, Green, and Co., 1895.

KuPER, Adam. Culture. The Anthropologists' Account. Cambridge, Massachusetts, Harvard University Press, 1999. 
LEPENIES, Wolf. Between Literature and Science: the Rise of Sociology. Cambridge e Paris, Cambridge University Press / Éditions de la Maison des Sciences de l'Homme, 1988.

LÉVY-BruHL, Lucien. Préface. In: FrAZER, James George. Le Cycle du Rameau d'or. Études comparées d'histoire des religions. Volume XII. Bibliographie et table des matières. Paris, Librairie orientaliste Paul Geuthner, 1930, pp.7-8.

MALINOWSKI, Bronislaw. Sir James George Frazer: A Biographical Appreciation. In: A Scientific Theory of Culture and Other Essays. Nova Iorque, Oxford University Press, 1960, pp.177-221.

PONTES, Heloisa. Intérpretes da metrópole. História social e relaçóes de gênero no teatro e no campo intelectual, 1940-1968. São Paulo, Editora da Universidade de São Paulo / Fapesp, 2010.

RAMASSOTE, Rodrigo. Cartografia do conhecimento antropológico. Revista de Antropologia (60/1), São Paulo, Departamento de Antropologia, FFLCH/USP, 2017, pp.309-316.

Rossi, Gustavo. O intelectual feiticeiro. Edison Carneiro e o campo de estudos das relaçôes raciais no Brasil. Campinas, Editora da Unicamp, 2015.

SAHLINS, Marshall. Captain James Cook; or, The Dying God. In:

Islands of History. Chicago, The University of Chicago Press, 1987, pp.104-135.

SMITH, Patti. Just Kids. Nova Iorque, Ecco, 2010.

SPEnCER, Baldwin; GiLlen, F. J. The Native Tribes of Central Australia. Londres, Macmillan and Co., 1899.

STOCKING, Jr., George W. On the Limits of "Presentism" and "Historicism" in the Historiography of the Behavioral Sciences. In: Race, Culture, and Evolution. Essays in the History of Anthropology. Chicago, The University of Chicago Press, 1982, pp.1-12.

. Outcast from the Islands. Frazer, The Golden Bough, and Modern Anthropology. In: Delimiting Anthropology. Occasional Inquiries and Reflections. Madison, The University of Wisconsin Press, 2001, pp.147-161. 
STRATHERN, Marilyn. Out of Context. The Persuasive Fictions of Anthropology. Current Anthropology (28/3), Chicago, The University of Chicago Press, 1987, pp.251-281.

TAussig, Michael. Mimesis and Alterity. A Particular History of the Senses. Nova Iorque e Londres, Routledge, 1993.

VAlÉRY, Paul. Préface. In: FrAZER, Sir James. La Crainte des morts. Paris, Émile Nourry, Éditeur, 1934, pp.5-9.

VICKERY, John B. The Literary Impact of The Golden Bough. Princeton, Princeton University Press, 1976. 